\title{
Influence of two synchronizers on the motor activity of the dog in semi-liberty
}

\author{
C Dolisi, C Ozon, D Crenesse, JL Ardisson \\ with the technical assistance of R Governatori and PJ Molla \\ Université de Nice-Sophia Antipolis, Faculté de Médecine, Laboratoire de Physiologie, \\ Chemin de Valombrose, F-06034 Nice Cedex, France
}

(Received 17 July 1990; accepted 13 October 1990)

\begin{abstract}
Summary - The motor activity of five dogs was recorded in three different experimental situations: A: free access to food and water during a 12:12 LD cycle; B: free access to food and water during constant lighting; $\mathrm{C}$ : a single meal per 24 hours at a set time during a 12:12 LD cycle. This study was designed to determine the possible influence of the two synchronizers (light-dark cycle, single daily meal) on the duration and pattern of motor activity in these five dogs over $24 \mathrm{~h}$. The motor activity of all five dogs in situation $A$ was predominantly diurnal. In situations $B$ and $C$, the duration and pattern of motor activity over 24 hours were modified in a divergent manner. The motor activity of dog 1 was not influenced by the single daily meal synchronizer. By contrast, the motor activity of dog 3 was not influenced by the light-dark cycle synchronizer. In the three other dogs, the two synchronizers had a similar influence, but differed in intensity. No common pattern of sensitivity to the two synchronizers was observed for these five animals. Each subject had its own specific reactivity and sensitivity that could only be determined by individual observations.
\end{abstract}

motor activity / light-dark cycle / constant light / food availability / food intake / dog

Résumé - Influence de deux synchroniseurs sur l'activité motrice du chien en semi-liberté. L'activité motrice de 5 chiens a été enregistrée dans 3 situations expérimentales :

- situation A: alimentation ad libitum, en cycle LD 12:12;

- situation $B$ : alimentation ad libitum en éclairement continu $L L$;

- situation C: un repas à heure fixe par $24 \mathrm{~h}$ en cycle $L D$ 12:12.

Le but du travail était de rechercher l'influence éventuelle des 2 synchroniseurs, alternance $L D$ et alimentation à heure fixe, sur la durée et la répartition dans les $24 \mathrm{~h}$ de l'activité motrice de ces 5 chiens.

En situation $A$, tous les chiens ont une activité motrice à prédominance diurne. En situation $B$ et $C$, la durée et la répartition, dans les $24 \mathrm{~h}$, de l'activité motrice sont modifiées de façon divergente chez les 5 chiens. L'activité motrice du chien 1 est influencée par le synchroniseur alternance LD. A l'opposé, l'activité motrice du chien 3 est surtout influencée par le synchroniseur repas à heure fixe. Chez les 3 autres chiens, on observe une influence conjointe mais d'importance variable des 2 synchroniseurs.

En définitive, il n'est pas possible de proposer un modèle commun décrivant la sensibilité de ces 5 chiens aux 2 synchroniseurs étudiés. Chaque individu présente une réactivité et une sensibilité qui lui sont propres et ne peuvent être connues que par l'observation individuelle. 


\section{INTRODUCTION}

Numerous studies performed under ad libitum conditions have demonstrated that motor activity and food intake in certain species such as rat (Hunt et al, 1939; Finger, 1951; Kayser, 1978; Armstrong et al, 1980; Rosenwasser et al, 1981) and hamster (Aschoff et al, 1973; Zucker and Stephan, 1973) are essentially nocturnal, whereas in other species such as monkey (Sulzman et al, 1977) and dog (O'Connor and Potts, 1969; Ganz and Kappen, 1980) such behavior is especially diurnal. The light-dark (LD) cycle is a strong synchronizer of the circadian rhythm of food intake and motor activity in most of these animals. Under free running conditions, the spontaneous rhythms of food intake and motor activity generally exhibit a period greater than 24 hours. This has been observed for the rat (Boulos et al, 1980; Rosenwasser et al, 1981), the hamster (Aschoff et al, 1973) and the monkey (Sulzman et al, 1977).

In the absence of a light-dark cycle, it has been shown that other factors can entrain the circadian rhythm of motor activity. Under constant light (LL), periodic presentation of food is a strong synchronizer of motor activity in rat (Edmonds and Adler, 1977; Rosenwasser et al, 1981) and monkey (Sulzman et al, 1977). Interaction of the light-dark synchronizer and the periodic food access synchronizer on motor activity in the rat has been studied by several authors. While animals were generally subjected to a 12:12 LD cycle and had access to food at a preset time during the light phase, results varied. For Gibbs (1979) and Edmonds and Adler (1977), the rat almost completely inverses its motor activity pattern when it has access to food during the light phase. By contrast, Coleman et al (1982) showed that this animal conserves its motor activity in the dark phase, although this author did note anticipatory spurts of activity before meals, as reported by Boulos and Terman (1980). Few studies (Mugford, 1977; Ardisson et al, 1981; Ganz and Kappen, 1980) have been carried out on the dog, and, to our knowledge, none has specifically investigated the interaction of these two synchronizers on the motor activity of this animal.

We previously described three types of drinking behaviour dependency on both light-dark alternation and meal timing in the dog (Ozon et al, 1987). The present study was designed to study the respective influence of these two synchronizers on the duration and pattern of motor activity over 24 hours in the dog. This study was carried out on the same five animals to identify any possible convergent reactions of the two behaviours (Ozon et al, 1987).

\section{MATERIALS AND METHODS}

Five dogs were studied (1: male mongrel, 8 years old, weighing $18 \mathrm{~kg} ; 2$, female mongrel, 6 years old, weighing $23 \mathrm{~kg}$; 3 : male mongrel, 6 years old, weighing $22 \mathrm{~kg}$; 4 : female beagle, 5 years old, weighing $15 \mathrm{~kg}$; 5 : male beagle, 6 years old, weighing $16 \mathrm{~kg}$ ). During the experiment, each animal was housed in a $30 \mathrm{~m}^{2}$ room at a constant temperature $\left(22{ }^{\circ} \mathrm{C} \pm 2{ }^{\circ} \mathrm{C}\right)$ and a relative humidity of $60 \% \pm 10 \%$. The room was lit artificially from 700 to $1900 \mathrm{~h}(12 \mathrm{~h})$. Intake of water and food was noted continuously, as described previously (Ardisson et al, 1981). Dogs were fed with a dry preparation (UAR 121). Motor activity was recorded continuously by a Doppler radar system. The recording shape allowed body movements to be distinguished from walking activity which is only held for measuring motor activity. Short periods of still standing included in walking activity were also recorded.

Each dog was studied in three situations:

Situation A: free access to food and water; light phase from 700 to $1900 \mathrm{~h}$ (12:12 LD). Results were used to assess the evolution of hour- 
ly means for motor activity and food intake over $24 \mathrm{~h}$.

Situation B: free access to food and water with constant lighting; same measurements as in situation $A$.

Situation C: access to food limited to between 1830 and $1900 \mathrm{~h}$ every day; lighting from 700 to $1900 \mathrm{~h}(12: 12 \mathrm{LD})$. Results were used to determine the hourly means for motor activity of each dog over a 24-h period.

Situations A, B and C were separated by approximately 15 months. Animals were returned to their kennels between experiments. Each situation was distributed at random over the year to avoid any possible seasonal influences. All of the experiments were performed between May 1980 and March 1984. Dogs were first weighed according to a previously described protocol (Ardisson et al, 1981). During all the experiments, weight variation never exceeded $5 \%$ in all five animals.

Before beginning situations $B$ or $C$, the dogs were placed in situation $A$ for $7 \mathrm{~d}$ to verify the stability of their food intake behavior and body weight. These $7 \mathrm{~d}$ were not included in the results.

Data obtained in these experiments were used to calculate: the mean daily motor activity (min) of each dog ( \pm SEM); evolution of the mean motor activity (min) over $24 \mathrm{~h}$ in situations $A, B$ and $C( \pm$ SEM); the mean daily food intake (g) of each dog $( \pm$ SEM); evolution of the mean food intake $(\mathrm{g})$ over $24 \mathrm{~h}$ in situations $\mathrm{A}$ and $\mathrm{B}( \pm$ SEM).

One-way analysis of variance (ANOVA) was used for statistical comparison of the different situations.

\section{RESULTS}

\section{Situation A}

\section{Food intake}

Analysis of mean hourly food intake over $24 \mathrm{~h}$ revealed that three dogs essentially ate during the light phase (fig 1). Dog 1 ate its daily food ration exclusively during the light phase. Dogs 4 and 5 had similar food intake behaviors; they ingested $85 \%$ (4) and $84 \%(5)$ of their total intake during this phase. Dogs 2 and 3 ate their daily food ration during the entire $24 \mathrm{~h}$ period, and the amounts ingested were slightly larger (12 to $20 \%$ ) during the day than at night (table I). The maximum hourly food intake periods for all five dogs occurred during the light phase (fig 1). Two dogs exhibited maximum food intake at the beginning of this phase ( 1 and 5 at $700 \mathrm{~h}$ ), while two others had their maximum in the middle of this phase ( 3 at $1300 \mathrm{~h}$ and 4 at $1100 \mathrm{~h}$ ). Maximum food intake for the last dog occurred during the second half of the light phase (2 at $1800 \mathrm{~h}$ ).

\section{Motor activity}

As shown by the mean hourly figures for motor activity over $24 \mathrm{~h}$, the motor activity of all five dogs was essentially diurnal (fig 2). Diurnal activity represented $87 \%$ (1), $63 \%(2), 68 \%(3), 78 \%(4)$ and $70 \%(5)$ of the total daily activity (table II).

Maximum motor activity for four of the dogs occurred during the first hour of the light phase (dogs $2,3,4,5)$. Maximum activity for dog 1 occurred two hours after the start of the light phase. For dogs 2, 3, 4 and 5 , motor activity remained at a mean level during the remainder of the light phase, then decreased in the dark phase, but never dropped to zero. Only dog 1 showed a decline in activity beginning at $1500 \mathrm{~h}$ (fig 2).

\section{Food intake and motor activity}

Activity in dogs 1,4 and 5, who ate most of their food during the light phase, was also essentially diurnal. However, in these three animals, the proportion of activity in the light phase was always slightly lower than the proportion of food ingested during this phase. By contrast, in dogs 2 and 3 , the 

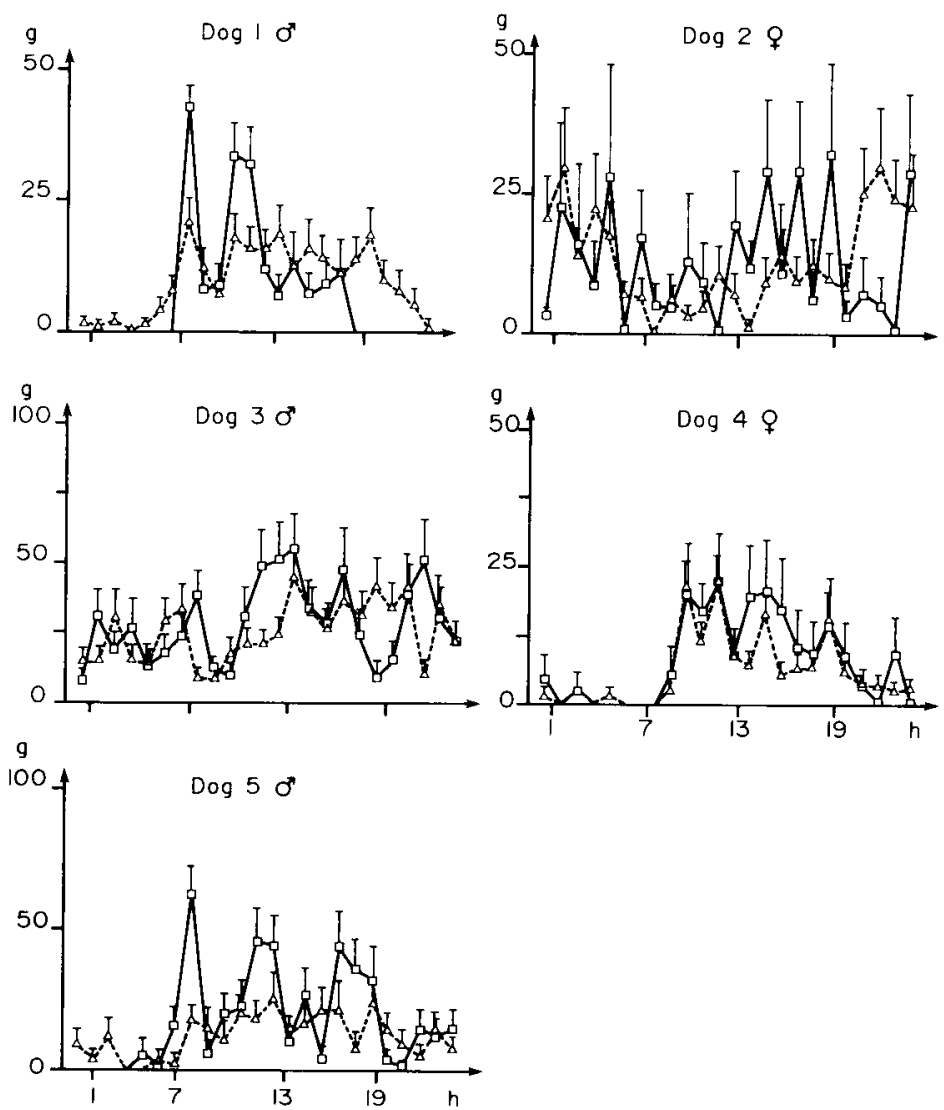

Fig 1. Mean hourly food intake (+ SEM) for five dogs. The curves $(-\square-\square-$ ) show an average of 19 (dogs 2 and 3 ), 20 (dogs 1 and 5 ) and 21 (dog 4) observation days in situation A. The curves $(-\Delta-)$ show an average of $27(\operatorname{dog} 5), 30(\operatorname{dog} 3), 34(\operatorname{dog} 1), 41(\operatorname{dog} 2)$ and $68(\operatorname{dog} 4)$ observation days in situation B. Dark phase between $19.00 \mathrm{~h}$ and $07.00 \mathrm{~h}$, in situations $\mathrm{A}$.

proportion of diurnal activity was superior to the proportion of food ingested during this same phase.

\section{Situation $B$}

\section{Food intake}

Comparison of food intake during constant lighting and during a light-dark cycle (table l) warrants several observations: dog 1 ate a supplementary amount of food between $700 \mathrm{~h}$ and $1900 \mathrm{~h}$ that increased its $24 \mathrm{~h}$ total food intake in a highly significant manner; dog 2 modified its food intake pattern over $24 \mathrm{~h}$, but the total amount ingested per day remained the same as in situation A (table I); dog 3 conserved the same eating pattern and the total amount of food ingested per day did not differ significantly from that in situation $A$ (table I); dogs 4 and 5 maintained approximately the same patterns, although they significantly re 
Table I. Mean values ( \pm SEM) of food intake $(g)$ in the dark phase and in the light phase, and daily total for each dog and for each situation. Statistical comparison of the quantity of food ingested in situations $B$ and $C$ with that in situation $A$. Comparison of food intake in situation $C$ and $S$ um in situation A.

\begin{tabular}{|c|c|c|c|c|c|c|}
\hline \multirow{2}{*}{ Dog No } & \multirow{2}{*}{$\begin{array}{c}\text { Situation } \\
\text { B }\end{array}$} & \multirow{2}{*}{$\begin{array}{c}\text { Nb days } \\
34\end{array}$} & \multicolumn{3}{|c|}{ Results } & \multirow{2}{*}{$\begin{array}{c}\text { (Anova) } \\
p<0.001 \\
\text { NS } \\
p<0.001\end{array}$} \\
\hline & & & $\begin{array}{l}19 \mathrm{~h}-7 \mathrm{~h} \\
7 \mathrm{~h}-19 \mathrm{~h} \\
\text { Sum }\end{array}$ & 1 & $\begin{array}{l}113.56 \pm 15.95 \\
348.29 \pm 19.66 \\
461.85 \pm 17.04\end{array}$ & \\
\hline \multirow[t]{3}{*}{$10^{7}$} & $A$ & 20 & $\begin{array}{l}19 h-7 h \\
7 h-19 h \\
\text { Sum }\end{array}$ & $\begin{array}{l}d \\
l\end{array}$ & $\begin{array}{l}0 \\
357.55 \pm 20.11 \\
357.55 \pm 20.11\end{array}$ & $\begin{array}{l}- \\
- \\
-\end{array}$ \\
\hline & c & 22 & $\begin{array}{l}19 h-7 h \\
7 h-19 h\end{array}$ & $\begin{array}{l}d \\
l\end{array}$ & $\begin{array}{l}0 \\
272.55 \pm 19.10\end{array}$ & $\rho>\overline{0} .01$ \\
\hline & B & 41 & $\begin{array}{l}19 h-7 h \\
7 h-19 h \\
\text { Sum }\end{array}$ & 1 & $\begin{array}{r}230.66 \pm 18.91 \\
75.17 \pm 12.59 \\
305.83 \pm 22.30\end{array}$ & $\begin{array}{c}p<0.01 \\
p<0.01 \\
\text { NS }\end{array}$ \\
\hline \multirow[t]{3}{*}{28} & A & 19 & $\begin{array}{l}19 h-7 h \\
7 h-19 h \\
\text { Sum }\end{array}$ & 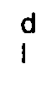 & $\begin{array}{l}119.58 \pm 23.88 \\
185.42 \pm 40.10 \\
305.00 \pm 48.15\end{array}$ & $\begin{array}{l}- \\
-\end{array}$ \\
\hline & $\mathrm{C}$ & 27 & $\begin{array}{l}19 h-7 h \\
7 h-19 h\end{array}$ & d & $\begin{array}{l}0 \\
296.56 \pm 37.35\end{array}$ & $\overline{\mathrm{NS}}$ \\
\hline & B & 30 & $\begin{array}{l}19 h-7 h \\
7 h-19 h \\
\text { Sum }\end{array}$ & 1 & $\begin{array}{l}335.75 \pm 23.26 \\
305.57 \pm 16.25 \\
601.80 \pm 24.12\end{array}$ & $\begin{array}{c}\text { NS } \\
p<0.05 \\
\text { NS }\end{array}$ \\
\hline \multirow[t]{3}{*}{30} & A & 19 & $\begin{array}{l}19 h-7 h \\
7 h-19 h \\
\text { Sum }\end{array}$ & $\begin{array}{l}d \\
\text { l }\end{array}$ & $\begin{array}{l}297.47 \pm 37.14 \\
384.37 \pm 28.15 \\
681.84 \pm 55.96\end{array}$ & $\begin{array}{l}- \\
- \\
-\end{array}$ \\
\hline & C & 19 & $\begin{array}{l}19 h-7 h \\
7 h-19 h\end{array}$ & $d^{d}$ & $\begin{array}{l}0 \\
375.84 \pm 16.38\end{array}$ & $p<\overline{0.001}$ \\
\hline & B & 68 & $\begin{array}{l}19 h-7 h \\
7 h-19 h \\
\text { Sum }\end{array}$ & $\mathrm{L}$ & $\begin{array}{r}18.94 \pm 4.68 \\
126.13 \pm 7.93 \\
146.21 \pm 7.85\end{array}$ & $\begin{array}{c}\text { NS } \\
p<0.05 \\
p<0.01\end{array}$ \\
\hline \multirow[t]{3}{*}{$4 \%$} & $A$ & 21 & $\begin{array}{l}19 h-7 h \\
7 h-19 h \\
\text { Sum }\end{array}$ & $\begin{array}{l}d \\
l\end{array}$ & $\begin{array}{r}27.29 \pm 9.92 \\
160.86 \pm 13.02 \\
188.14-11.91\end{array}$ & $\begin{array}{l}- \\
- \\
-\end{array}$ \\
\hline & $c$ & 29 & $\begin{array}{l}19 h-7 h \\
7 h-19 h\end{array}$ & $\begin{array}{l}d \\
1\end{array}$ & $\begin{array}{l}0 \\
184.15-11.31\end{array}$ & $\overline{N S}$ \\
\hline & B & 27 & $\begin{array}{l}19 h-7 h \\
7 h-19 h \\
\text { Sum }\end{array}$ & 1 & $\begin{array}{r}75.70 \pm 11.25 \\
188.78 \pm 61.89 \\
264.48 \pm 16.34\end{array}$ & $\begin{array}{c}\text { NS } \\
p<0.05 \\
p<0.001\end{array}$ \\
\hline \multirow[t]{2}{*}{50} & $A$ & 20 & $\begin{array}{l}19 \mathrm{~h}-7 \mathrm{~h} \\
7 \mathrm{~h}-19 \mathrm{~h} \\
\text { Sum }\end{array}$ & $\begin{array}{l}d \\
1\end{array}$ & $\begin{array}{r}69.60 \pm 14.74 \\
355.60 \pm 14.70 \\
425.20 \pm 17.39\end{array}$ & $\begin{array}{l}- \\
- \\
-\end{array}$ \\
\hline & $\mathrm{C}$ & 14 & $\begin{array}{l}19 h-7 h \\
7 h-19 h\end{array}$ & $\begin{array}{l}d \\
1\end{array}$ & $\begin{array}{c}0 \\
301.21 \pm 10.05\end{array}$ & $p<\overline{0.001}$ \\
\hline
\end{tabular}



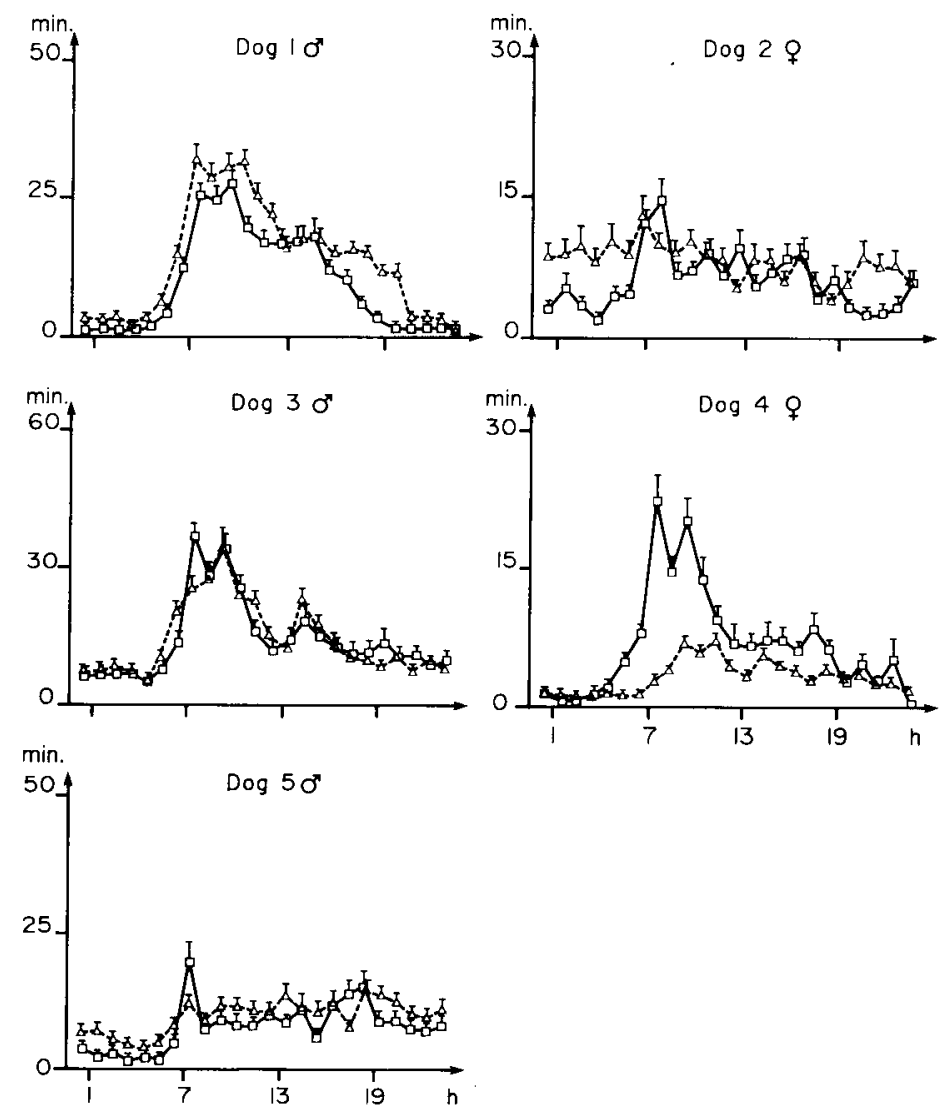

Fig 2. Mean hourly motor activity (+ SEM) for five dogs. The curves $(-\square-\square)$ show an average of 19 (dogs 2 and 3 ), 20 (dogs 1 and 5) and 21 (dog 4) observation days in situation A. The curves $(--\Delta--)$ show an average of $27(\operatorname{dog} 5), 30(\operatorname{dog} 3), 34(\operatorname{dog} 1), 41(\operatorname{dog} 2)$ and $68(\operatorname{dog} 4)$ observation days in situation $B$. Dark phase between $1900 \mathrm{~h}$ and $0700 \mathrm{~h}$, in situations $A$.

duced their food intake. This reduction was most marked in dog 5 (table I).

\section{Motor activity}

When the mean $24 \mathrm{~h}$ durations of motor activity in constant lighting are compared to those during the LD cycle (table II), several observations can be made: motor activity in dogs 1,2 and 5 increased by
$24 \%$ to $55 \%$. This increase was significant for dog 1. It occurred especially between $1900 \mathrm{~h}$ and $700 \mathrm{~h}$ for all three dogs. It was accompanied by marked levelling in the hourly activity pattern for dogs 2 and 5 . By contrast, data for dog 1 revealed only a prolongation of the mean activity period between $1600 \mathrm{~h}$ and $1900 \mathrm{~h}$ (fig 2); motor activity in dog 4 decreased very significantly over $24 \mathrm{~h}$, especially between $700 \mathrm{~h}$ and $1900 \mathrm{~h}$. This led to a very clear damp- 
Table II. Mean values ( \pm SEM) of motor activity $(\min )$ in the dark phase, and in the light phase, and daily total of each dog, for each situation and during the $1800 \mathrm{~h}-20000 \mathrm{~h}$ observation phase in situation C. Statistical comparison of motor activity in situations $B$ and $C$ with that in situation $A$.

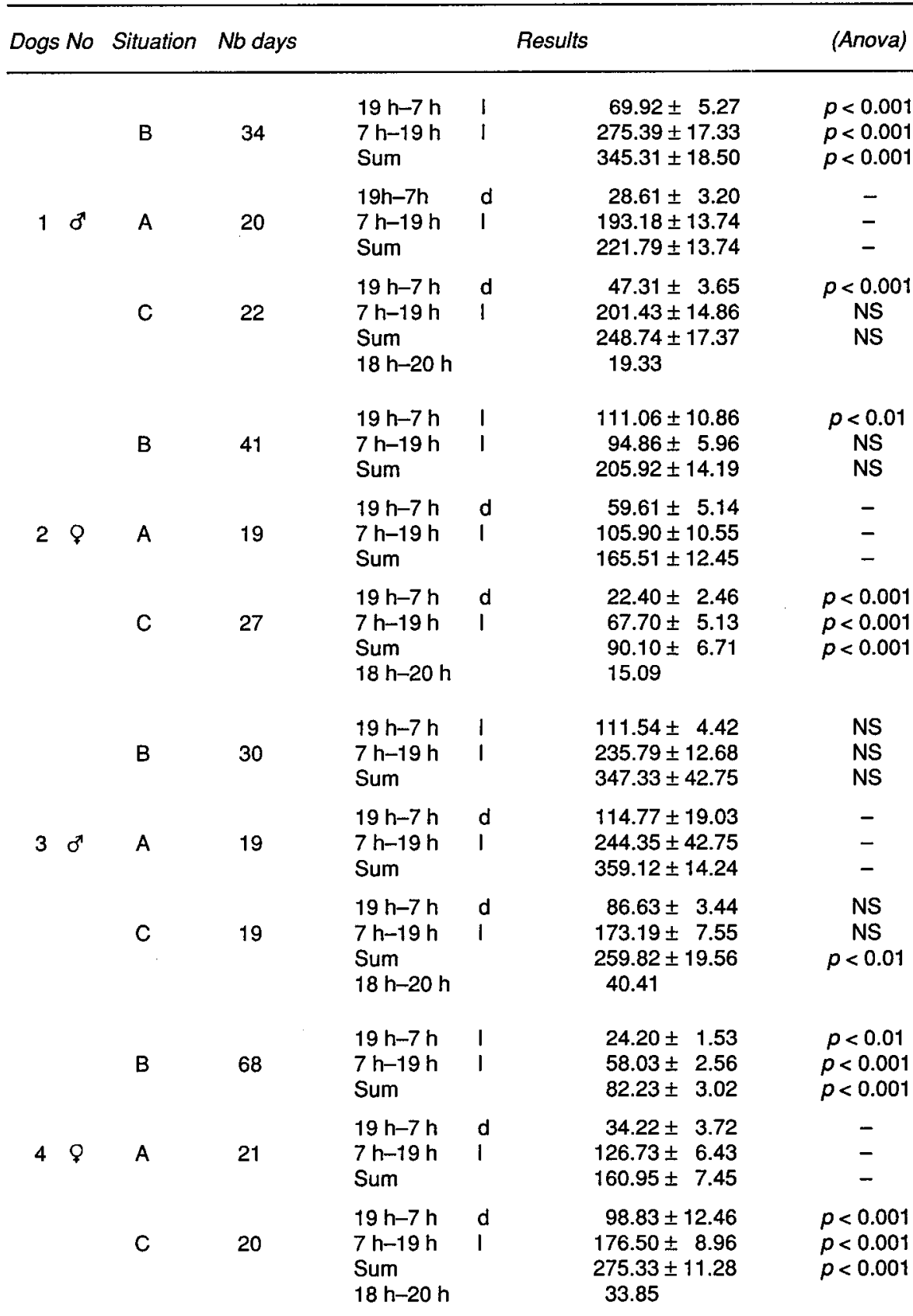




\begin{tabular}{|c|c|c|c|c|c|c|}
\hline & B & 27 & $\begin{array}{l}19 h-7 h \\
7 h-19 h \\
\text { Sum }\end{array}$ & $\begin{array}{l}1 \\
1\end{array}$ & $\begin{array}{r}95.71 \pm 3.88 \\
131.87 \pm 7.20 \\
227.58 \pm 39.84\end{array}$ & $\begin{array}{c}p<0.001 \\
\text { NS } \\
\text { NS }\end{array}$ \\
\hline \multirow[t]{2}{*}{$50^{\circ}$} & $A$ & 20 & $\begin{array}{l}19 h-7 h \\
7 h-19 h \\
\text { Sum }\end{array}$ & $\begin{array}{l}d \\
\text { d }\end{array}$ & $\begin{array}{r}53.27 \pm 12.17 \\
122.13 \pm 12.48 \\
175.40 \pm 22.77\end{array}$ & $\begin{array}{l}- \\
-\end{array}$ \\
\hline & C & 14 & $\begin{array}{l}19 h-7 h \\
7 h-19 h \\
\text { Sum } \\
18 h-20 h\end{array}$ & $\begin{array}{l}d \\
l\end{array}$ & $\begin{array}{r}119.64 \pm 4.64 \\
174.16 \pm 9.73 \\
293.80 \pm 11.82 \\
60.21\end{array}$ & $\begin{array}{c}p<0.001 \\
p<0.01 \\
p<0.001\end{array}$ \\
\hline
\end{tabular}

ing of its hourly motor activity pattern (fig $2)$; the 24 h motor activity duration of dog 3 remained identical to that in situation $A$. The pattern of this motor activity remained the same for $24 \mathrm{~h}$ (table II, fig 2).

\section{Food intake and motor activity}

Comparison of total daily food intake and the amount of daily motor activity in situations $A$ and $B$ reveals that three dogs exhibited parallel evolutions in their food intake and motor activity. Under constant lighting, dog 1 increased both its food intake $(+29 \%)$ and its motor activity $(+55 \%)$, dog 4 simultaneously reduced its food intake $(-22 \%)$ and motor activity $(-48 \%)$, and dog 3 did not modify either its food intake or motor activity. Different evolutions were noted for the other two dogs. Under constant lighting, dog 2 modified its hourly food intake pattern (fig 1), but there was no change in the total amount ingested per day; by contrast, the duration of this animal's mean daily motor activity increased $(+24 \%)$, although in a non-significant manner, except from $1900 \mathrm{~h}$ to $700 \mathrm{~h}$. For dog 5, eating behavior and motor activity evolved in opposite ways: reduction in food intake $(-37 \%)$ and increase in daily motor activity $(+29 \%)$.

In short, elimination of the LD synchronizer produced both convergent and diver- gent modifications in eating behavior and motor activity of these five dogs. Only the food intake behavior and motor activity of $\operatorname{dog} 3$ were independent of this synchronizer.

\section{Situation C}

\section{Food intake}

Dogs 2 and 4 ingested an amount of food equivalent to that in situation $A$ in a single meal (table I). By contrast, animals 1, 3 and 5 significantly reduced their daily food intake by $23 \%$ to $44 \%$ (table I).

\section{Motor activity}

The mean hourly motor activity profiles for all 5 dogs were fairly similar to those in situation $A$, except from $1800 \mathrm{~h}$ to $2000 \mathrm{~h}$. When only a single meal was given between $1830 \mathrm{~h}$ and $1900 \mathrm{~h}$, the duration of motor activity in all dogs increased from $1800 \mathrm{~h}$ to $2000 \mathrm{~h}$ (fig 3). This increase represented $6 \%$ to $12 \%$ of the total daily activity in situation $\mathrm{C}$ (table II).

Mean daily levels of motor activity evolved in various ways: dog 1 did not significantly modify its mean daily motor activity duration; dogs 2 and 3 significantly decreased this duration, by $27 \%$ and $45 \%$ respectively. This decrease occurred 
equally in the light and dark phases; dogs 4 and 5 strongly increased their daily motor activity (by $57 \%$ to $71 \%$ ). This increase was relatively higher during the dark phase.

\section{Food intake and motor activity}

Only one animal (dog 3) presented a parallel evolution in its food intake and motor activity, which were reduced significantly. The other two dogs that also reduced their food intake (1 and 5) exhibited either no significant modification in activity (1) or a significant increase in motor activity (5). The dogs that ate the same amount of food as in situation A (2 and 4) displayed opposite evolutions in their motor activity: motor activity decreased significantly in dog 2 but increased markedly in dog 4 .

In summary, four dogs $(2,3,4,5)$ significantly modified (increased or decreased) their motor activity when access to food
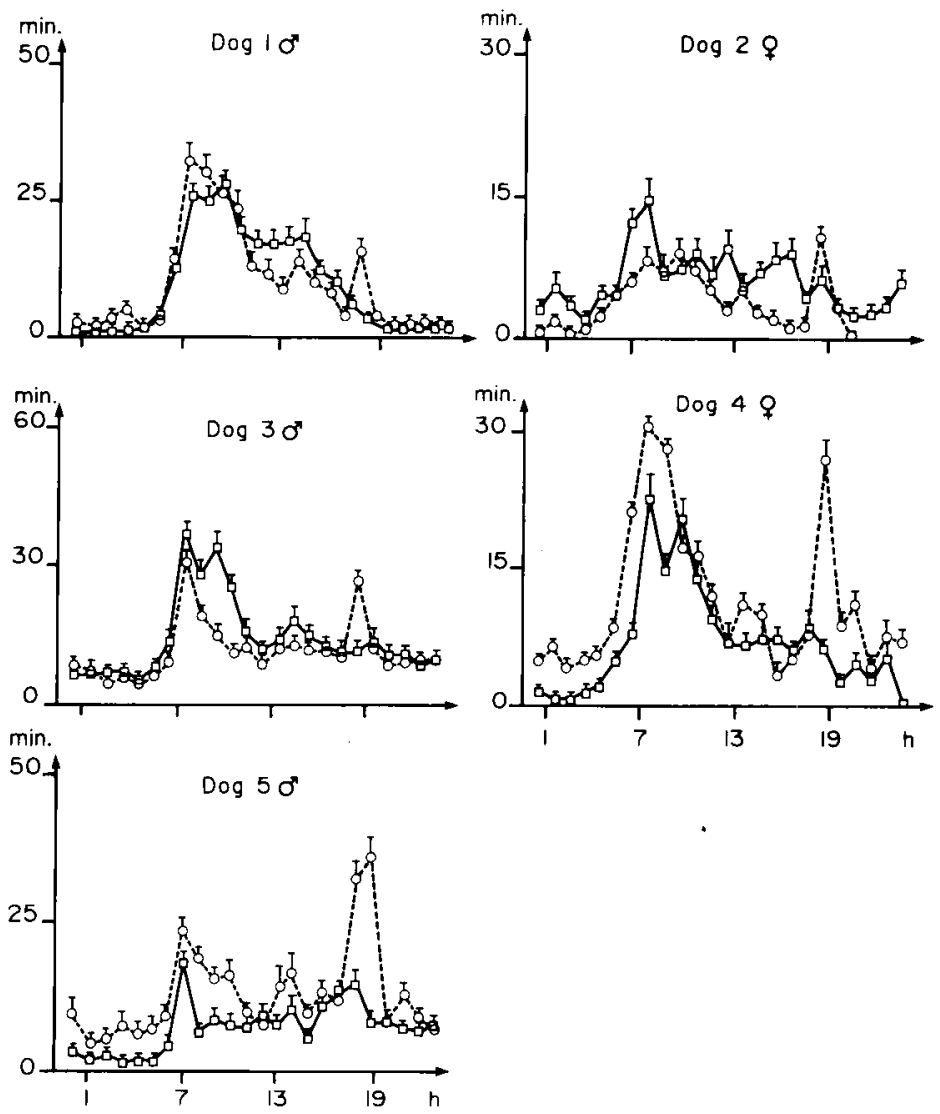

Fig 3. Mean hourly motor activity (+ SEM) for five dogs. The curves $(-\square-\square)$ show an average of 19 (dogs 2 and 3), 20 (dogs 1 and 5) and 21 (dog 4) observation days in situation A. The curves $(\bullet 0 \cdot 0 \cdot \cdot)$ show an average of $14(\operatorname{dog} 5), 19(\operatorname{dog} 3), 22(\operatorname{dog} 1), 27(\operatorname{dog} 2)$ and $20(\operatorname{dog} 4)$ observation days in situation C. Dark phase between $19.00 \mathrm{~h}$ and $07.00 \mathrm{~h}$, in situations $\mathrm{A}$ and $\mathrm{C}$. Meal between $1830 \mathrm{~h}$ and $1900 \mathrm{~h}$, in situation $\mathrm{C}$. 
was limited to half an hour every 24 hours. Only dog 1 failed to show any significant modification in motor activity compared to situation $A$.

\section{DISCUSSION}

Regardless of the protocol considered, this study provides further evidence for the existence of marked inter-individual differences. These differences were most marked in situations $B$ and $C$. They are noted even in same race dogs, for instance, dogs 4 and 5 were very similar in situation $A$, but reacted in a very different manners in the two other experimental situations. Moreover, no two identical patterns of evolution were ever seen in situations $B$ and $C$ for the five dogs. Such interindividual variability is not specific to the dog species. It has also been observed in the rat. Several authors (Richter, 1927; Hunt and Schlosberg, 1939; Finger, 1951; Edmonds and Adler, 1977; Gibbs, 1979) have observed different eating behavior and motor activity from one subject to another when individual data is analyzed.

Measurement of motor activity in situation A confirmed that the dog belongs to those species with predominantly diurnal behavior (Mugford, 1977; Ganz and Kappen, 1980) as opposed to such nocturnal species as the rat (Richter, 1927; Hunt and Schlosberg, 1939). All five dogs concentrated more than $60 \%$ of their activity in the light phase ( $87 \%$ for dog 1$)$.

Suppression of the light-dark cycle was followed by an increase in motor activity for dogs 1,2 and 5. For all of these three dogs, this increase occurred especially during the phase corresponding to the dark phase in situation $A$. These results suggest that the light-dark cycle is a synchronizer of motor activity variations, and that the dark had a more or less intense inhibitory action on these three animals.

The motor activity of dog 4 was very different from that of dogs 1,2 and 5 under constant light conditions. The hypothesis of an inhibitory effect of the dark phase on activity is not applicable for this animal. The endogenous rhythm at the origin of motor activity variations was weak in this animal. By contrast, the light-dark cycle was both a very active synchronizer of this rhythm and a strong stimulant of the level of activity.

The responses are very different for two female dogs (2 and 4), indicating that sex is not a determinant factor.

Dog 3 showed no significant modification in its motor activity under constant lighting. In this animal, variations in the level of motor activity were determined by a very strong endogenous rhythm which was not influenced by the light-dark cycle synchronizer under the experimental conditions.

In all the five dogs, the single daily meal was accompanied by a transient increase in motor activity in the hour in which food was ingested and, to a lesser degree, in the succeeding hour. This motor activity peak linked to food intake always represented only a small fraction of the animals' total daily activity. No motor activity peak was observed in any of the five dogs in the hours preceding food intake, as has been described in the rat. In this last species, numerous authors (Edmonds and Adler, 1977; Rosenwasser et al, 1981; Coleman et al, 1982) have reported supposedly "anticipatory" activity before meals when feeding is restricted to once or twice per 24 hours. Likewise, none of the five animals displayed any post-feeding activity comparable to that described in the dog by Ganz and Kappen (1980). Reduction of the average daily activity in two on the dogs (2 
and 3) suggests that the single meal had an inhibitory effect on their motor activity. The synchronizing effect of the single meal was not very strong in these two dogs, because the relative distribution of motor activity between the light and dark phases remained similar to that during control situation A. By contrast, dogs 4 and 5 showed a strong increase in their motor activity, particularly in the dark phase. For these two animals, the daily single meal was a strong stimulant of activity and a synchronizer whose action was stronger than in the two previous dogs. Finally, only one dog (1) seemed to be insensitive to the single daily meal synchronizer. The degree of independence appears very large because modifications of food intake were very marked in this situation. Indeed, this animal ate only one meal a day instead of the average of three in situation $A$, and it ingested only $75 \%$ of its usual daily intake.

\section{CONCLUSION}

Situations $B$ and $C$ led to behavioral modifications that were very different from one subject to another. Analysis of all motor activity data reveals that the respective influences of the two synchronizers were variable from one animal to the other. In dog 1 , the single meal time synchronizer had no significant influence under experimental conditions. In dog 3, the light-dark cycle did not appear to have any significant influence. Dogs 2 and 5 were highly affected by the feeding time synchronizer but relatively less so by the light-dark cycle synchronizer. However, in these two animals, the feeding time had opposite effects on the average duration of motor activity. Finally, only dog 4 was sensitive to both synchronizers in a comparable way.

Overall, this study confirms the interest of individual studies (Richter, 1927; Hunt and Schlosberg, 1939; Finger, 1951; Edmonds and Adler, 1977; Gibbs, 1979) in addition to population studies. Data obtained for the two synchronizers did not permit identification of any reactivity pattern common to all five dogs. Each subject presented a specific reactivity and sensitivity that can only be determined by individual observations.

\section{REFERENCES}

Ardisson JL, Dolisi C, Ozon C, Crenesse D (1981) Caractéristiques des prises d'eau et d'aliments spontanées chez des chiens en situation ad libitum. Fhysiol Behav 26, 361370

Armstrong S, Coleman G, Singer G (1980) Food and water deprivation: changes in rat feeding, drinking, activity and body weight. Neurosci Biobehav Rev 4, 377-402

Aschoff J, Figala J, Poppel E (1973) Circadian rhythms of locomotor activity in the golden hamster (Mesocricetus auratus) measured with two different techniques. $J$ Comp Physiol Psychol 85, 20-28

Boulos Z, Rosenwasser AM, Terman M (1980) Feeding schedules and the circadian organization of behavior in the rat. Behav Brain Res 1, 39-65

Boulos Z, Terman M (1980) Food availability and daily biological rhythms. Neurosci Behav Rev 4, 119-131

Coleman GJ, Harper S, Clarke JD, Armstrong S (1982) Evidence for a separate mealassociated oscillator in the rat. Physiol Behav 29, 107-115

Edmonds SC, Adler NT (1977) Food and light as entrainers of circadian running activity in the rat. Physiol Behav 18, 915-919

Finger FW (1951) The effect of food deprivation and subsequent satiation upon general activity in the rat. $J$ Comp Physiol Psychol 44, 557-564

Ganz H, Kappen F (1980) Contribution to the control of the locomotor activity of the dog. Methods Find Exp Clin Pharmacol 2, 7-15 
Gibbs FP (1979) Fixed interval feeding does not entrain the circadian pacemaker in blind rats. Am J Physiol 236, R249-253

Hunt JMV, Schlosberg H (1939) General activity in the male white rat. $J$ Comp Psychol 28, 23-38

Kayser C (1978) Analyse du rythme circadien de l'activité motrice du rat blanc par l'emploi de plusieurs agents pharmacologiques agissant sur les monoamines cérébrales. Arch Int Physiol Bioch 86, 1099-1116

Mugford RA (1977) External influences on the feeding of carnivores. The Chemical Senses and Nutrition. Academic Press, New York, 25-50

Oatley K (1971) Dissociation of the circadian drinking pattern from eating. Nature 229, 494-496

O'Connor WJ, Potts DJ (1969) The external water exchanges of normal laboratory dogs. $Q t$ $J$ Exp Physio/ 54, 244-265
Ozon C, Dolisi C, Ardisson JL, Crenesse D, Gastaud M (1987) Synchronization of dog drinking behaviour by light/dark thythm and food availability. J Interdiscip Cycle Res 18, 3, 205-217

Richter CP (1927) Animal behavior and internal drives. Ot Rev Biol 2, 307-343

Rosenwasser AM, Boulos Z, Terman M (1981) Circadian organization of food intake and meal patterns in the rat. Physiol Behav 27, 33-39

Rosenwasser AM, Pelchat RJ, Adler NT (1984) Memory of feeding time: possible dependence on coupled circadian oscillators. Physiol Behav 32, 25-30

Sulzman FM, Fuller CA, Moore-Ede MC (1977) Environmental synchronizers of squirrel monkey circadian rhythms. J Appl Physiol 43, 795-800

Zucker I, Stephan FK (1973) Light-dark rhythms in hamster eating, drinking and locomotor behavior. Physiol Behav 11, 239-250 